\title{
SYNERGY IN A TEAM - QUALITY ANALYSIS OF CONDITIONS ${ }^{1}$ SYNERGIA W ZESPOLE - ANALIZA JAKOŚCIOWA WARUNKÓW WYSTĘPOWANIA
}

\author{
Monika Jasińska \\ Poland, Siedlce University of Natural Sciences and Humanities \\ Faculty of Economic and Legal Sciences \\ Nr ORCID: 0000-0001-9231-4469, e-mail: monika.jasinska@uph.edu.pl
}

\begin{abstract}
Synergy is a powerful tool that emerges when the social potential is improved and high activity is achieved. This is a feature of well-functioning and continuously learning teams. The aim of the study is to examine circumstances that may favour synergy in team work. Teams functioning in a company that is typical for a learning organisation were selected to conduct analysis in the case study. In order to collect the data, the author applied grounded theory and surveys along with descriptive and analytical methods. The study proved that team synergy conditions are the quality of cooperative relations, entrepreneurial potential and measurable effects of joint action. Keywords: synergy, team, cooperation, development, active approach
\end{abstract}

\begin{abstract}
Streszczenie. Siłą, która wyłania się w momencie doskonalenia potencjału społecznego i uzyskiwania dzięki niemu wysokiej aktywności działania jest synergia. Właściwość ta jest cechą sprawnie działających i nieustannie uczących się zespołów. Celem badania opisanego w niniejszym artykule jest wskazanie, jakie okoliczności mogą sprzyjać wystapieniu zjawiska synergii we wspólnej pracy. Do analizy stanowiącej studium przypadku wybrano zespoły funkcjonujące $w$ firmie o cechach organizacji uczącej się. Dane uzyskano na podstawie teorii ugruntowanej oraz badań sondażowych. Zastosowano metody opisowe i analityczne. Dostrzeżono, że warunkami pojawienia się synergii w zespołach jest jakość relacji we współpracy, potencjał przedsiębiorczy oraz wymierne efekty wspólnego działania.
\end{abstract}

Słowa kluczowe: synergia, zespół, współpraca, rozwój, organizacja ucząca się, aktywne postawy

\section{Introduction}

For any organisation, it is important to have the ability to perceive opportunities and to set new directions of development, in order to achieve efficiency in functioning. Ideas are always being sought on how to create an original management concept. This is a strategy that will generate a modern, innovative and effective organisation. However, this way of thinking requires, from the management, both competence and experience. Therefore, the responsiveness to perceiving values in the internal potential of an organisation becomes important. And obviously, awareness of the key role people play in any organisation turns out to be the first in line. This is the basis for building and implementing processes and providing the necessary competences. Interestingly, in learning organisations, the aspect of the value of team learning and acting together emerges based on this awareness. Thus with the defined value being effective team work, organisations can more boldly determine the path of their development. There is clear evidence that by increasing the effectiveness of teamwork, you can improve the quality of work, ideas, knowledge, skills, and trigger new potential. Therefore, it is important to develop every organisation member's awareness to the assumption of innovation which should, by all means, be the foundation of teamwork. Understanding that the ability to combine multiple points of view, compile knowledge and experience is valuable to deal with any emerging problems. This way of thinking will increase the opportunities of an organisation not only for efficient functioning, but above all it will involve potential in further development. Practice shows that effective teams are also able to offer much more than individuals to any organisation. This applies mainly to the frequency and quality of generating ideas, taking initiatives and flexibility in implementation. Innovation is a feature for

\footnotetext{
${ }^{1}$ The paper has been prepared on the basis of a fundamental research project - Synergy and Social Capital of Modern Organisations. The project was financed by the National Science Centre with funds allocated on the basis of decision-DCE number 2011/01 / BHS4 / 04810.
} 
high activity (Ali Taha, Sirková, Ferencová, 2016) and team feeling (Salleh, Fareed, Yusoff, Saad, 2018). In addition, one of the most important aspects of effective teamwork synergy is, the team's feature, which naturally emerges along with the growth of a team and its potential.

\section{Circumstances encouraging synergy in a team}

There are many views on how organisations should function today and in the future (eg: Arbab, Abaker, 2018; Park, Zhang, Keister, 2019, Loermans, 2002, Aggestam, 2006). What unites these visions is the condition of activity in work. The strength that strengthens this assumption is the organisational culture (Essawi, Tilchin, 2013, Hood, Jacobson, Van Buren, 2011; Al-Shammari, Al-Am, 2018). It is the basis for shaping proactive behaviour at work (Brunetto, Xerri, Nelson, 2014). This type of behaviour is often understood as: active personality, personal initiative, self-efficacy, accepting responsibility, future-oriented behaviour that causes change (Crant, 2000; Grant, Ashford, 2008). Proactive behaviours are beneficial for individuals, teams and organisations (Detert, Burris, Harrison, Martin, 2013). They are equally important for activity in work and in cognitive activity.

The second role of an organisational culture is that it builds and supports awareness of the need for continuous learning at different levels of activity. In organisations, the learning process includes individuals, teams and entire organisations. This is done through intuition, interpretation and institutionalisation. It requires proper design, set-up, running and maintenance by an inspired leadership (Bratianu, 2015). This is a purposeful process that requires the right approach and participation of every individual in an organisation. An example of this is the concept of five disciplines developed by P. Sange. In this philosophy he pointed out that building a learning organisation requires focus on system thinking (Sange, 2014; Senge, Kleiner, Roberts, Ross, Roth, Smith, 1999; Zeeman, 2017). It is about looking at an organisation as a holistic learning model. It can be treated as a model that allows an organisation to adapt to the environment, generate new knowledge and use it to develop creative activities. The ability to transform collaborative learning into the power of creating a new quality of knowledge is the foundation for a learning organisation. Thus an organisation builds a competitive advantage (Senge, 2010; Bratianu, 2015).

Organisations that build their value using, at all levels, growth of learning abilities create opportunities for increasing efficiency. Recognising new opportunities, they stimulate entrepreneurial activity, they become open to introducing innovative changes, and they are ready to be successful (Senge, 2010). There are many arguments justifying the need to include learning and improvement in the life of the organization, just to name the most frequent ones: the desire to achieve better results, improving efficiency and quality, efficiency and openness of communication, customer satisfaction, building a competitive advantage, introducing changes, greater flexibility of action (Morales, Montesa, Joverb, 2007; Lippit, 1997; Loermans, 2002; Rusly, Corner, Sun, 2012). It should also be remembered that strengthening this process should be a thorough combination of people, ideas, resources, systems, and leadership. This way of thinking is important to make use of all organisation's capabilities to enable its development (Albrecht, 2003).

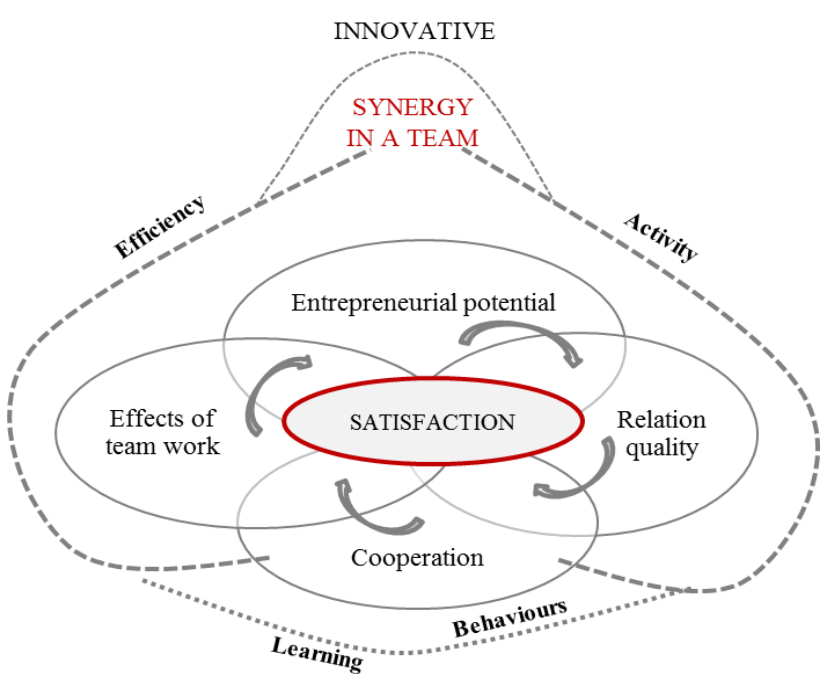

Figure 1. Conditions of synergy in a team Source: author's concept.

It is increasingly noticed that in a culture that promotes innovation (Krejčí, Šebestová, 2018), the development of an organisation strengthens synergy. This is a phenomenon that emerges from the quality of teamwork. It requires proactive behaviour and an efficiently implemented mutual learning process in an organisation. Synergy arises in a natural way as a result of stimulating at least two factors. This is an effect that was considered greater than the sum of individual separate activities. Synergy (in the aspect of organisational behaviour) is a state signalled by the experienced increase of satisfaction as a result of cooperation and subsequent tangible effects (Jasińska, 2015). The high level of cooperation, implied by the quality of relations shaped in a given environment, should be taken as the basis for the synergy. Synergy will occur thanks to the impact of a given strength - social potential - in a given system (team, organisation) (Corning, 1997). Based on the analysis of literature and research and in order to comprehensively describe the circumstances of synergy, see Figure 1 that presents synergy's key conditions. 


\section{Research Methodology - description of the research procedure}

The whole process of the research aimed at diagnosing synergy conditions in team work consists of three main stages presented in Figure 2.

To start with, the activities focus on the implementation of qualitative research. In this context, the basis for obtaining empirical data is the application of the grounded theory strategy. This was done based on individual and group surveys and observation techniques (214 people in total). Secondly, 22 teams (200 people in total) underwent preliminary surveys. The aim of this stage was the basic verification of empirical areas and general assumptions selected in the grounded theory. Moreover, this part of the procedure was also used to analyse developed research tools, which indicated the need to have the variables more thoroughly developed and specified in the measurement. The research covering the first two stages was based on the case study method ("P-M" company). This selection decision, supported by research projects implemented for the company's needs, was the result of a preliminary practical assessment. This enabled a better approach to recognise the grounds for the teams' functioning and to observe what the quality of team work is all about. The "P-M" company was extremely appealing from a research perspective since it is hugely diversified: the profile of activity, complexity of processes, dynamics and directions of change, management (including the philosophy of quality and knowledge management), the size of the company and the number of teams operating in it.

The third dimension of the research procedure concerns conducting research on a large and diversified group of companies and teams. The survey was conducted among 1394 members of designated teams operating in companies recognised as learning organisations. A further step in the research procedure was the statistical analysis of the obtained data, which in turn determined the variables and dependencies relevant to the quality of the joint operation. In the end, the whole process resulted in the creation of the final version of the model and methods for analysing the synergy conditions in teams. The end result is the SYNGRAF ${ }^{\mathrm{TM}}$, a tool that allows analysis and control of the team's operating parameters. (The analyticalcontrolling technical device is a modular map including the methods of its liaisons, for which the Patent Office of the Republic of Poland granted the right for registration of an industrial design under the number Wp.26875 and the trademark, filed on 28.08.2018). In order to look for a synergy trademark, PCA-based methods and regression model, programme (dedicated application) has been recommended. On this basis, it is possible to select from a specific set of data, the so-called synergistic variables. These are two variables mutually reinforcing their activity, which, jointly, result in an increase in the purpose function (in the study it is a manifestation of synergy recognised as a satisfaction of team work).

The process of determining the conditions of synergy in teams is complex. Bearing in mind the large amount and value of the material collected, this article focuses on the highlighted first and second stage of the procedure (see Figure 2). This approach seems justified in order to maintain the appropriate logic in the presentation of the evidence path of the obtained empirical data. Therefore, the remaining part of research results on a large group - the quantitative research stage will be presented in subsequent publications.

The application of the grounded theory strategy was preceded by a preliminary exploration phase based on the results of applied research (the effects of these studies were implemented into practice, and the proposed solutions improved specific processes). This was treated as an inspiration for creating the concept of qualitative research. The conclusions drawn and scientific consultations held with the management staff, triggered and directed further research activities. At this stage, the validity of the observation areas was determined. The findings on the behaviour of people both in organisations and teams defined the procedure specifying selection of the test sample and subsequent development of the data code key. The indication of teams for the study was based on the criteria of a targeted choice. The teams' lists created by the HR department and in consultation with managers took into account three main assumptions: the type, size of the team and the level of efficiency. Finally, 22 teams participated in qualitative research (200 people - employees and leaders) including: large (over 11 people), medium (7-11 people), small (up to 6 people), project, managerial, operational, advisory, trouble shooting, and with different levels of operational efficiency. Additionally, the study was attended by middle and senior management (14 people).

The concept of recognising synergy conditions in team work based on the case study in "P-M" focused on: interviews and observations in teams and preliminary surveys. The basis of the first part of the analysis are in-depth individual interviews with members of 7 project teams (2 large, 2 small and 3 medium). 


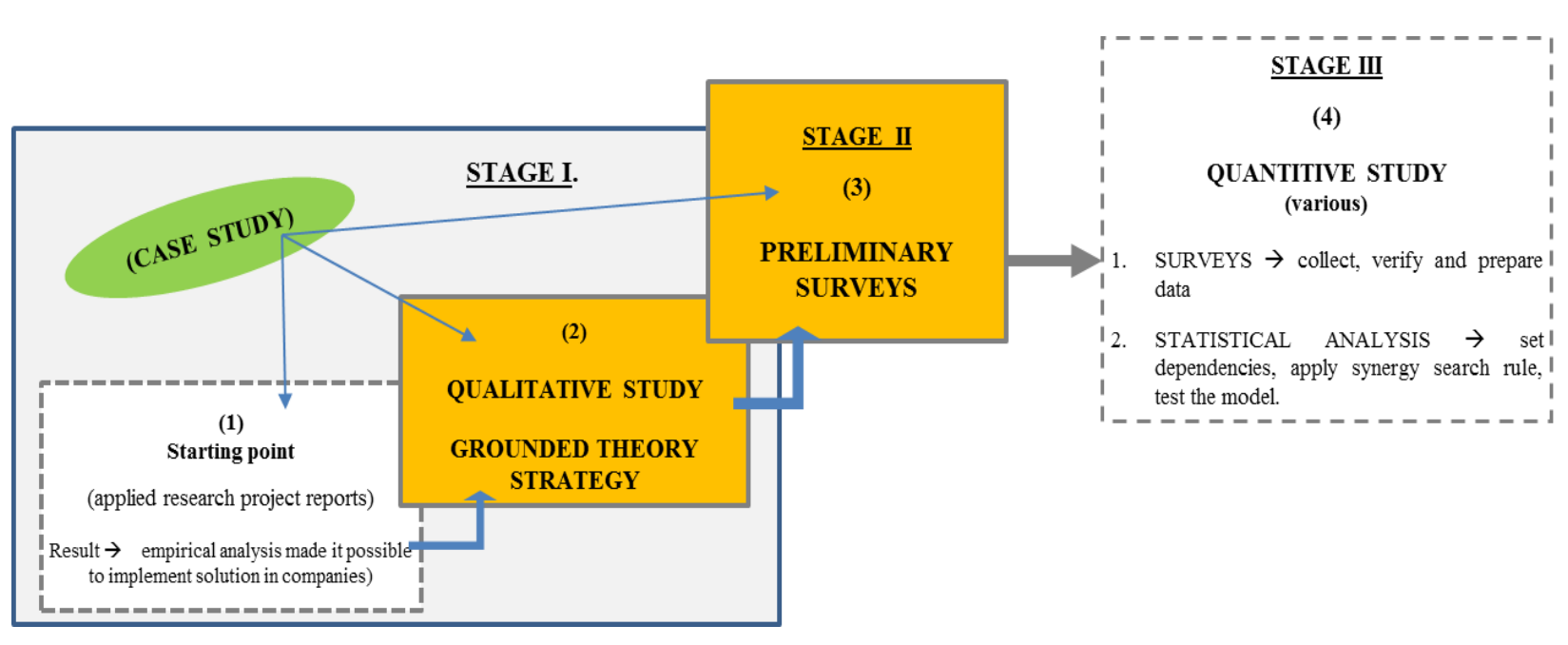

Figure 2. Research procedure to determine the synergy conditions in teams Source: author's concept.

In total, 59 people joined the study (employees and team leaders). The research presented an open approach to any new circumstances and information. Apart from interviews with team members participating in the survey, 14 people of the managerial personnel have also been interviewed. They provided an objective description of findings and assessment of the way the teams operate and the conditions for managing team work. This enabled recognising new and consolidating the already possessed knowledge, which in turn led to some interesting dimensions of the functioning of groups, behaviours, reactions and expectations of people in team work. Successfully collected material was saved mainly in the form of notes from interviews. The free interviews established the basic concepts and features significant for the relationship, the set-up of activities, quality and effects of team work. Guided by the principle of the grounded theory, systematically collected empirical material was analysed on an ongoing basis. It allowed verifying the scenario of subsequent interviews and emerging with more typical findings (Konecki, 2009). The results collected during individual interviews allowed outlining a new dimension of information, which was obtained as a result of the discussion in teams, that must undergo more clarification.

The second part of the grounded strategy included group interviews - focus group, conducted in 15 teams of different profiles in terms of size ( 5 large, 5 medium and 5 small), gender ( 3 manager, 3 project, 3 problem, 3 functional, 3 advisory) and the level of effectiveness (11 highly effective and 11 average). The result of conversations during group interviews was recorded in two ways: audio (voice recorder used) and in the form of notes, according to the previously established data entry code. In this part of the study, participants were more open to digital recording. The coding method developed ensured proper transcription, and later analysis of the collected material. With the implementation of subsequent group interviews, more and more key issues, important for the quality of team work emerged, along with characteristic definitions, impressions, experiences about analogy and understanding of synergy. It seemes very interesting, especially since the word synergy was not used throughout the entire qualitative study. Only in the final part of the group interviews, when the respondents naturally began to use the term "synergy", the interviews were focused more on deliberately describing this context of teamwork.

The moment, the respondents repeatedly expressed the same or very similar answers the study had been considered theoretically exhausted in terms of collected research material. At that time, a decision was made to stop the sampling process and the analysis started (Charmaz, 2014). Categories, indicators, characteristics describing behaviours and the way the team performs during teamwork were established as a result of the data elaboration. The frequency and validity of the answers indicated has been coded. The developed material made it possible to perform a qualitative analysis that was to determine the most characteristic indicators and characteristics. Next, a preliminary statistical analysis of qualitative data was carried out. The coefficient of rho-Spearman correlation was used to observe the first significant relationships. The final stage of the qualitative study was the preliminary development of the research tool. The questionnaire was built on the basis of data established in practice, which was used at the next stage of research. 
The second stage of the research procedure is associated with a preliminary survey that diagnoses conditions and quality of teamwork. The area of main issues selected on the basis of the grounded theory was subjected to basic quantitative verification. The method used in the statistical analysis is the Person's correlation coefficient $r$, confirmatory factor analysis (CFA) and the multiple correlation coefficient (R2). The effect of the statistical elaboration was to estimate the created model by determining the main dependencies, values of factor loads and determining the percentage of the explained variance within the studied variables. The aim of this stage was also to test the constructed research tool. The first version of the survey, in the substantive part, consisted of 120 elements and 5 questions characterising the research sample. The claims used in the design were assigned to 5 research areas: cooperation, quality of relations, entrepreneurial potential, effects of team work, and satisfaction. The first four areas were defined by three variables. On average, 9 characteristic features describes each of them.
The basis for the assessment of 12 groups of variables was the aggregated index as the average points from the measurement of previously set-up features. The area of satisfaction was determined directly by 8 categories. Individual features, were measured by 5 -point Likert scale, where 1 is the lowest and 5 the highest value.

The survey included team members who participated in both individual and group interviews in the first part of the procedure giving a total number of 200 people. Table 1 shows the characteristics of the team members.

The concepts, phenomena, behaviours, categories and features discovered and defined on the basis of the grounded theory come directly from the observed and surveyed group of team members (Konecki, 2011; Charmaz, 2014). At this point of the procedure the researcher structured the collected material. And finally, the outcome and drawing the main assumption of the study were possible to realise due to the systematically collected, developed and analysed data during field research.

Table 1. Demographic and occupational characteristics of members of the surveyed teams

\begin{tabular}{|c|c|c|c|c|c|c|}
\hline \multirow{2}{*}{ Gender } & \multirow{2}{*}{$\begin{array}{c}\text { category } \\
\text { result }\end{array}$} & \multicolumn{3}{|c|}{$F$} & \multicolumn{2}{|c|}{$M$} \\
\hline & & \multicolumn{3}{|c|}{112} & \multicolumn{2}{|c|}{88} \\
\hline \multirow{2}{*}{ Age } & category & $>30$ & $30-39$ & $40-49$ & $50-59$ & $\leq 60$ \\
\hline & result & 8 & 80 & 79 & 27 & 6 \\
\hline \multirow{2}{*}{ Education } & category & \multicolumn{2}{|c|}{$>$ average } & \multicolumn{2}{|c|}{ average } & higher \\
\hline & result & \multicolumn{2}{|c|}{-} & \multicolumn{2}{|c|}{18} & 182 \\
\hline \multirow{2}{*}{$\begin{array}{l}\text { Time in team } \\
\text { (in years) }\end{array}$} & category & $>1$ & $1-2$ & \multicolumn{2}{|c|}{$3-4$} & $<5$ \\
\hline & result & 21 & 34 & \multicolumn{2}{|c|}{51} & 94 \\
\hline \multirow{2}{*}{$\begin{array}{l}\text { Total length } \\
\text { of employment } \\
\text { (in years) }\end{array}$} & category & $\geq 5$ & $6-15$ & $16-25$ & $26-35$ & $<35$ \\
\hline & result & 15 & 30 & 62 & 54 & 39 \\
\hline
\end{tabular}

\section{Results and discussion}

Bearing in mind the research procedure presented in Figure 1, this part of the article will present the results of the first two stages of the study. This seems justified due to the maintenance of an appropriate order of presentation of the empirical material. Activities related to obtaining data within the framework of the grounded theory are a very important point in the entire research process. They allowed recognising and describing the circumstances of the emergence of force, which arises on the basis of activity and creates the quality of working together.
The presentation of the results will be divided into two parts: qualitative research and preliminary surveys.

\section{The results of qualitative research}

The scenario of qualitative research is based on the results of applied research (realised for the company's needs in order to introduce improvements), that are elaborated in the reports. All that proved, that team work plays an important role in increasing organisational effectiveness. This applies not only to the functioning of the teams themselves, but also to building cooperation between teams. It was observed that the basis for the efficiency of a team's activities is the quality of the relations between 
colleagues. Apt use and sharing of knowledge and skills at work proved to be important in this respect. The research also shows that employees' attitudes and behaviours translate into joint effects at work, but they also depend on the resources of knowledge and skills. In addition, the study emphasised the important role of enhancing activities of the management in shaping positive attitudes and team work. The results of the conducted analysis are an inspiration and a starting point for commencing qualitative research. It is based on empirical curiosity and the need to improved learning, which creates true quality in team work.

The next step of presentation and analysis of data is related to the qualitative research stage. The empirical material obtained on the basis of the grounded theory allows seeing the complexity of the conditions determining the way a team works. And what is more, it makes us consider the need to build the awareness of all stakeholders setting up mutual dependence. In this context, the inclusion of system thinking becomes the basis for creating a new quality of relationship.

The first result of qualitative research was the emergence of concepts and terms related to teamwork. The most characteristic answers were: quality of relations, cooperation, setting up of activities, effects of team work, team work, efficiency, activity, trust, team capabilities, strengthening of joint work, entrepreneurial activity, joint initiatives, satisfaction, team results, team management, communication in a team, knowledge sharing, mutual learning, development, team effectiveness, competence, consistent action, responsibility for work, commitment, integrity and justice at work, mutual assistance, prompt information, joint responsibility, rules of cooperation, joint care for the quality of work.

The second consequence of the implemented grounded theory strategy was to determine the main categories, their importance and frequency of indication. Based on the analysis of the empirical material, 16 main categories were built, which form the basis for the recognition and description of team quality conditions. In this area, the following were indicated: creating and developing contacts at work, regulating relationships, communication, trust, team potential, work planning, competences, teamwork, performance, self-development, personal activity, team activity, motivation, work atmosphere, behaviour at work, difficult situations in working together. An additional category that emerged with theoretical saturation and is of great empirical interest is satisfaction. However, this is not the usual kind of satisfaction, general pleasure or satisfaction. As emphasised by respondents, this is a special expression of satisfaction (satisfaction "bonus", "plus", "premium", satisfaction*), which occurs when people start to cooperate with each other, open to each other, are responsible for quality achieved, they notice a common effect, they feel the progress that motivates action. On this basis, they experience an additional force that energises the team and each member of the team, increases its activity, creates additional energy of action. Hence, with respect to all findings, it becomes quite clear that "satisfaction*" and synergy share similar perceptions, descriptions and impressions. The grounded theory also enabled establishing associations about synergy. The most distinctive answers are: pleasure of being in a team, additional benefit, added value, new quality, additional contribution to team work, high level of activity and concentration in action, something additional, something important in the team, sense of accomplishment, profit, bonus for team.

The third result of qualitative research is the indication of variables based on previously defined categories. In accordance with theoretical and practical knowledge, 7 research areas were established within the scope of: cooperation, the effect of team work, effort in team work, quality of relations, management, team potential, satisfaction. Taking into account the results obtained in the first part of the qualitative research, an attempt was made to determine if there is a correlation, and if so, what it is in the aspect of the main variables. The basic information on this subject was provided by the assessment obtained by determining the rhoSpearman correlation coefficient. The finding shows that between the 7 variables the dependence ranges from moderate (minimum $r_{s}=0.45$ ) to very high ( $\max$ $r_{s}=0.84$ ), which is shown in Table 2. The strongest correlation occurs in the cooperation - the effects of team work $\left(r_{s}=0.84\right)$ and the quality of the relationship - satisfaction $(r s=0.82)$. This significant dependence may point to one of the arguments that reveals the circumstances that favour the synergy in a team. Now, considering the subsequent values of the coefficient in Table 2, it can be noticed that high correlations (from $r_{s}=0.79$ to $r_{s}=0.72$ ) show interrelations between the 4 variables mentioned above. Therefore we may assume, that the key conditions for the emergence of synergy in team work relate to the quality of relationships, cooperation, the effects of team work and satisfaction. In the entire system of 7 variables distinguished in the study, three variables present the weakest relationship composed with the others: the potential of the team, the effort of team work, management. Considering however, the correlation value, this result is not as weak as to exclude these variables from further analysis. This is perhaps a signal for different arrangement of variables in the analysis. 
Table 2. Relationship between the main variables defining the synergy conditions in a team by the rho-Spearman coefficient of correlation

\begin{tabular}{lcc}
\hline \multicolumn{1}{c}{ Variable } & Value rs & Strength of correlation \\
\hline cooperation - effect of team work & 0.84 & very high \\
relation quality - satisfaction & 0.82 & \\
\hline satisfaction - effect of team work & 0.79 & high \\
quality of relationships - cooperation & 0.75 & \\
cooperation - satisfaction & 0.73 & \\
relationship quality - effect of team work & 0.72 & \\
team potential - effect of team work & 0.66 & \\
management - effect of team work & 0.65 & \\
management - satisfaction & 0.65 & \\
management - cooperation & 0.64 & \\
Management - quality of relations & 0.63 & \\
team's potential - quality of relations & 0.62 & \\
team's potential - satisfaction & 0.61 & \\
\hline quality of relationship - effort in team work & 0.59 & \\
team potential - cooperation & 0.58 & \\
Effort in a joint action - satisfaction & 0.56 & \\
effort in team work - effect of team work & 0.55 & \\
effort in team work - management & 0.51 & \\
effort in team work - cooperation & 0.47 \\
team's potential - effort in team work & 0.46 \\
team's potential -management & 0.45 & \\
\hline p <0.001 & & \\
\hline
\end{tabular}

\section{The results of quantitative research}

The adopted qualitative research was the starting point of further development of the data analysis. The theoretical and practical knowledge impose the need to correct the system of the previously proposed variables. The correction concerned three dimensions in the analysis (team's potential, effort of team work, management) of variables that generated the weakest correlation composed with the others. The team's potential and the activities of the managers in managing a team have been combined into one research area. The joint possibility of entrepreneurial activity and its support, make perfect ground for the newly emerged variable. On the other hand, upon repeated analysis, the set of features describing the effort of team work, was included in the variable cooperation, which portrayed better the course of this process. The new list proposes 5 research areas describing the synergy conditions in team work. The main variables in the model are: entrepreneurial potential, quality of relations, cooperation, effects of team work and satisfaction. The new dimension of the research areas was subsequently verified. For this purpose, the constructed research tool consisted of 120 elements ( 12 traits describe satisfaction, 108 describe
12 distinguished variables). And thereafter, the research procedure initiated the next stage of data collection and analysis - preliminary surveys.

The material obtained as a result of the survey has been used for statistical analysis. The confirmation factor analysis (CFA) was the first to verify the model. This was carried out with reference to 12 variables describing the main research areas. To better describe the synergy conditions in the team it is crucial to determine the loads of factors that structure the validity of variables and in order to preserve the model's quality it is necessary to assess whether non-standardised path factors are significant. In this context, the analysis takes into account the determination of the percentage of the explained variance (R2). The next step is to assess the relationship between the 4 main research areas (latent variables) based on Pearson's correlation coefficient. The results of the conducted analysis are presented in graphical form in Figure 3. The a Cronbach's coefficient of internal coherence has been determined for the analysed variables in order to increase the analytical reliability of the data. Validation of the research tool indicated high parameters $\alpha=0.898$. 


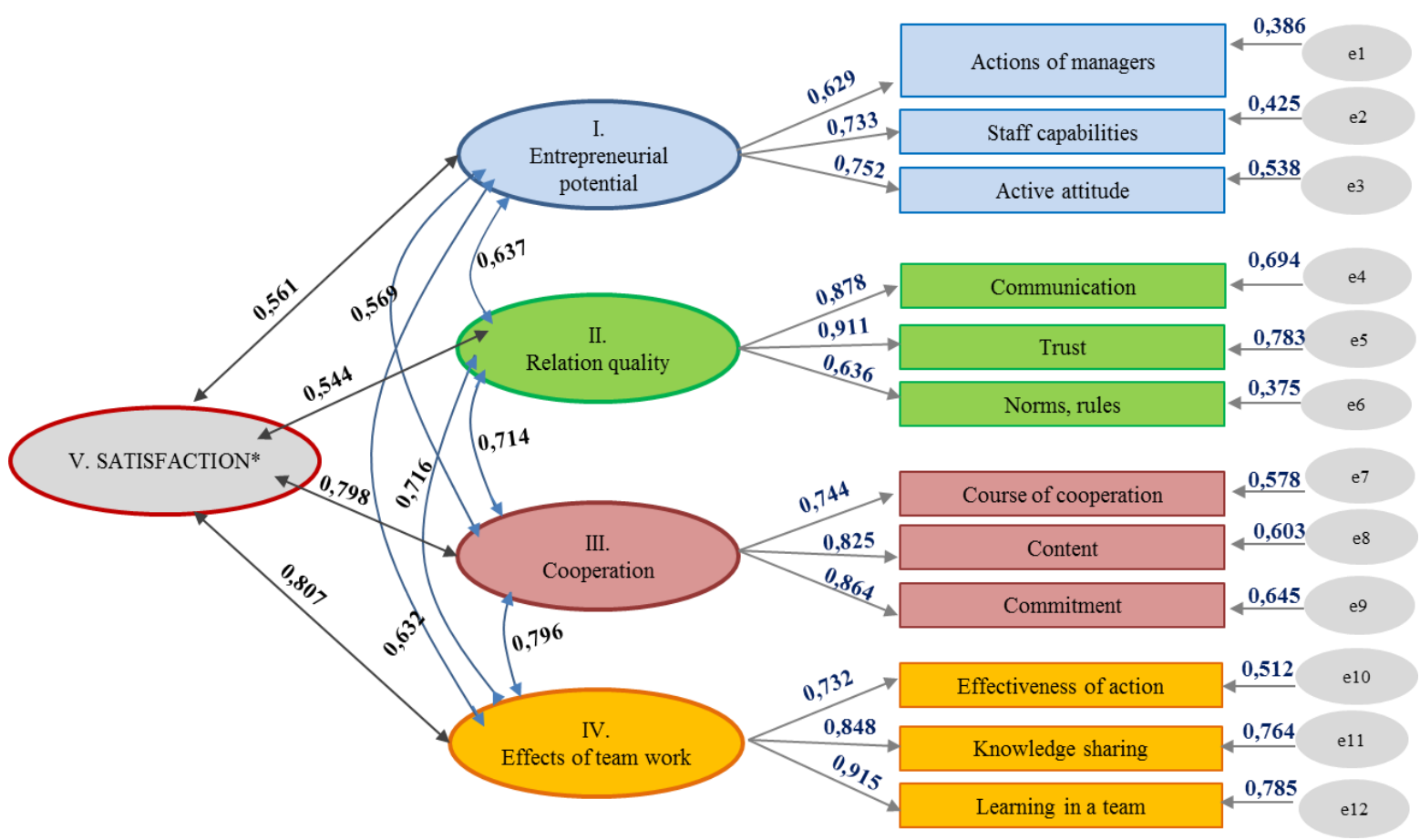

Figure 3. Confirmatory factor analysis model with correlated factors

Source: author's concept.

The confirmatory factor analysis assessment of the model based on 12 variables (Figure 3) indicates that factor loads have reached the desired value of 0.7 for 10 out of 12 variables. Hence, the outcome of the CFA verification presents a good match of individual claims to factors. In order to present data, reference was made to 4 levels of factor load values:

- level 1 - values $<0.9$;

- level 2 - values within 0.81 - 0.9;

- level 3 - values within 0.7 - 0.8;

- level 4 - values> 0.7 .

Level 1 concerns the variables learning in a team (0.915) and trust (0.911) and these 2 variables exceeded the value 0.9 giving the highest factor load. 4 variables, rated as high gave the factor load value exceeding 0.8 . This level 2, distinguished: communication (0.878), commitment (0.864), knowledge sharing (0.848) and satisfaction (0.825). The conducted analysis also indicates a fairly high value, exceeding 0.7 , of factor loads for 4 variables, which were assigned to level 3 that comprises: active attitude (0.752), course of cooperation (0.744), employee capabilities (0.733) and effectiveness of actions (0.732). At level 4, two variables were perceived that did not exceed 0.7 . These are the norms and principles (0.636) and the activities of the management (0.629). Nevertheless, the value of these loads can be considered an acceptable result, because it is close to the desired level. Taking into account the overall CFA score, it should be stated that for each of the 4 latent variables, an adequate matching of the claims to the factor was confirmed. The best match, however, can be seen in the context of factors: cooperation and the effects of team work.

The percentage of the explained variance (R2) was determined to substantiate the assessment quality of the factor analysis model. In the case of 9 variables, the result exceeds the desired value of 0.5 . These are variables which factor loads are greater than 0.7: team learning (0.785), trust (0.783), knowledge sharing $(0.764)$, communication $(0.694)$, commitment (0.645), content (0.603), collaboration (0.678), active attitude (0.538) and effectiveness (0.512). Although the factor load of capabilities of employees variable is $<0.7$, the $R 2$ reached 0.425 . This may indicate the need to verify claims in terms of their scope or accuracy. And probably, there are some hidden features that could provide more relevant explanation of the entrepreneurial potential factor along with two other variables, i.e. the activities of the management (0.386) and standards and principles (0.375), for which the R2 is $>0.5$. In the aspect of these parameters, the tool should also be verified, taking into account hidden features, due to the fact that these variables explain the variability of the factor below $40 \%$. When making an assessment of the identified conditions of synergy in teams, the main factors were also correlated. In general, all dependencies are positive, and most of them are significant. The strongest relation with other variables is demonstrated by the cooperation and effects of 
team work. Cooperation achieves a high correlation with satisfaction (0.798), the effects of team work (0.796) and the quality of relations (0.714). This means that the increase in the level of cooperation depends on ensuring a high quality of relations. In addition, it was found that the better the cooperation, the better the effects of team work, the team members feel an increase in satisfaction from the team's activities. The second factor - the effects of team work, apart from the cooperation factor, demonstrates significant dependencies with other variables. This is especially evident in relation to: quality of relationship (0.716), satisfaction (0.807) and entrepreneurial potential (0.632). The remaining relations between the main areas of the study (see Figure 3) indicate a moderate correlation. The results obtained on the basis of the analysis are the next argument that provides empirical evidence that the factors studied are crucial for creating the circumstances of synergy in team work.

\section{Conclusions}

The process of studying synergy conditions in a team is a complex activity and with this fact in mind, it required the development of an appropriate research procedure. The proposed method of identifying and establishing the conditions of synergy allowed presenting an appropriate evidence path. The applied procedure has taken into account the possibility of exploration and description of the phenomenon. The planned series of activities showed the legitimacy of the fact that the questionnaire can assess both the way a team operates and the activity of teamwork. However, to get the right quality of data it is vital to develop a set of tools using practical knowledge. That gave rise not only to research inspiration and knowledge about the team but, above all, the possibility to recognise and understand the multidimensionality of synergy. Referring to the results of the qualitative research and preliminary surveys, it can be stated that the proposed research methods enabled the proper collection and processing of data. The methods used at the stage of the analysis also allowed seeing key factors in creating conditions of synergy in a team. The first and second stages of the proposed research procedure were a valuable contribution to further studies and a strong foundation supporting the knowledge concerning synergy.

The study analysis and subsequent results enabled an assumption that well-formed entrepreneurial potential and adequately high quality of relations are the circumstances conducive to synergy. The developed empirical material also indicates the importance of proper organisation and the course of cooperation. It is extremely important in the context of achieving exceptional effects of team work. A special kind of satisfaction emerges from the quality and activity of a team, that creates extra energy and enhances the development process, which is, naturally, important in the context of the entire organisation.

\section{Tips for managers}

With the case study method applied, the examination resulted in several guidelines for managers supporting the creation of high quality team work and management of effective teams in an organisation:

1. The phenomenon of synergy in team work should be considered an extra boost when developing the quality of joint action and the organisation's efficiency. This is an additional contribution to team work that increases the efficiency of each unit as well as the entire team. Increased operational efficiency generates added value for the organisation, that comprises enhanced entrepreneurial activity, creativity and innovative behaviour. These values translate into the competitiveness of teams and organisations.

2. Synergy in a team is a multidimensional phenomenon that can be interpreted not only by quantitative but also qualitative measurement. It can be seen as a special kind of satisfaction satisfaction ${ }^{*}$ of joint action, which occurs when the team achieves high efficiency, and team members can feel the benefits of cooperation.

3. Direct observation of behaviours, sense of accomplishment and attitudes of people are prominent when identifying the manifestations of synergy in team work. Therefore, the team's performance should be regularly assessed in order to indicate favourable conditions for the occurrence of synergy. Thus, when creating the quality of teamwork, it is necessary to prepare employees, for them to be able to perceive and use all aspects indicative of an activity increase in a joint action. This specific team-based know-how is the factual value allowing for determining features of team's operations that create the real quality.

4. The quality of relations in team work is the basis for the efficiency of the activities undertaken by any team. Having said that, managers should inject, in the employees awareness, that the sense of interdependence, openness to knowledge sharing and readiness to offer and properly-exploit potential are clues for achieving high quality effects of team work. Now, to be able to strengthen the flow of knowledge in a team, executives should provide the right atmosphere at work, created by a high level of trust and communication. 
5. In order to create conditions for synergy in a team it is crucial to provide the simultaneous interaction of four factors: the quality of relations, cooperation, the effects of team work and satisfaction with team work. Shaping the quality of relations is important for building the attitude and maintaining a high value of cooperation, which generates a specific effect of joint action in team work. The quality of relations, cooperation and jointly achieved effects determine the satisfaction of joint action, which is an additional strength for the team.

6. And finally, it is necessary to build an appropriate level of activity in team work to achieve synergy. This, however, would not be possible without the competences and actions of the managerial personnel that supports the right level of activity in team work by constantly developing potential, shaping active behaviours and entrepreneurial attitudes of team members.

\section{Acknowledgements}

The paper has been prepared on the basis of a fundamental research project - Synergy and Social Capital of Modern Organisations. The project was financed by the National Science Centre with funds allocated on the basis of decision-DCE 2011/01 / BHS4 / 04810.

\section{References}

Aggestam, L. (2006). Learning Organization or Knowledge Management - Which came first, the chicken or the egg?, Information Technology and Control, Vol. 35, No. 3A.

Albrecht, K. (2003). The power of minds at work. Organizational intelligence in action, New York, NY: American Management Association.

Ali Taha, V., Sirková, M., Ferencová M. (2016). The impact of organizational culture on creativity and innovation, Polish Journal of Management Studies, Vol. 14 (1), 7-17.

Al-Shammari, M., Al-Am, Z. (2018). Organizational culture and job satisfaction in a telecommunications company in the kingdom of Bahrain, Polish Journal of Management Studies, Vol. 18 (1), 33-43.

Arbab, A.M., Mahdi, M.O.S. (2018). Human resources management practices and organizational excellence in public organizations, Polish Journal of Management Studies, Vol. 18 (2), 9-21.

Bratianu, C. (2015). Organizational Knowledge Dynamics: Managing Knowledge Creation, Acquisition, Sharing, and Transformation, Hershey: IGI Global, https://www.researchgate.net/ publication/2810328

69_Organizational_Knowledge_Dynamics_Managi ng_Knowledge_Creation_Acquisition_Sharing_ and_Transformation.
Brunetto, Y.O., Xerri, M.J., Nelson, S.A. (2014). Building a proactive engagement culture in asset management organizations, Journal of Management in Engineering, Vol. 30, No. 4.

Charmaz K. (2014). Grounded Theory in Global Perspective: Reviews by International Researchers, http://citeseerx.ist.psu.edu/viewdoc/download?doi= 10.1.1.858.8343\&rep=rep1\&type=pdf

Corning, P.A. (1997). Holistic Darwinism: "Synergistic Selection" and the Evolutionary Process, Journal of Social and Evolutionary Systems, Vol. 20 (4).

Crant, J.M. (2000). Proactive Behavior in Organizations, Journal of Management, Vol. 26(3).

Detert, J.R., Burris, E.R., Harrison, D.A., Martin, S.R. (2013). Voice Flows to and around Leaders: Understanding When Units Are Helped or Hurt by Employee Voice, Administrative Science Quarterly, Vol. 58.

Essawi, M., Tilchin, O. (2013). A Model of Knowledge Management Culture Change, American Journal of Industrial and Business Management, Vol. 3 No. 5.

Grant, A.M., Ashford, S.J. (2008). The dynamics of proactivity at work, In Staw B.M., Brief A. (eds.), Research in organizational behavior, Vol. 28, Greenwich, CT: JAI.

Hood J.N, Jacobson K.J.L., Van Buren H.J. (2011). Creating ethical organisational cultures by managing the reactive and proactive workplace bully, International Journal of Economics and Business Research, Vol. 3(1).

Jasińska, M. (2015). Synergy, the result of intelligent cooperation, http://www.irdo.si/skupni-cd/cdji/cd-irdo2015/referati/15-monika-jasinska-paper.pdf.

Konecki, K.T. (2011). Visual Grounded Theory: A Methodological Outline and Examples from Empirical Work, https://doi.org/10.5613/rzs.41.2.1.

Konecki, K.T., (2009). Teaching Visual Grounded Theory, Qalitative Sociology Review Vol. V (3), https://hrcak.srce.hr/file/106256.

Krejčí, P., Šebestová, J. (2018). Social innovation ties: a dilemma of product and employee orientation, Polish Journal of Management Studies, Vol. 17 (2), 123-133.

Lippit, M. (1997). Communication: Say What You Mean, Mean What You Say, Journal of Business Strategy, Vol. 18 (4).

Loermans, J. (2002). Synergizing the Learning Organisation and Knowledge Management, Journal of Knowledge Management, Vol. 6 (3).

Morales, V., Montesa F., Joverb A. (2007). Influence of Personal Mastery on Organizational Performance through Organizational Learning and Innovation in Large Firms and SMEs, Technovation, Vol. 27.

Park, S.H., Zhang, Y., Keister L.A. (2019). Governance innovations in emerging markets, Academy of Management Perspectives, In-Press, https://journals. aom. org/doi/10.5465/amp.2017.0177.

Rusly, F.H., Corner J.L., Sun, P. (2012). Positioning change readiness in knowledge management research, Journal of Knowledge Management, Vol. $16(2)$. 
Salleh, S.S.M.M., Fareed, M., Yusoff, R.Z., Saad, R. (2018). Internal and external top management team (TMT) networking for advancing firm innovativeness, Polish Journal of Management Studies, Vol. 18 (1), 311-325.

Senge, P., Kleiner, A., Roberts, C., Ross, R., Roth, G., Smith B. (1999). A Fifth Discipline: The Dance of Change: The Challenges of Sustaining Momentum in Learning Organizations, New York, Crown Business.

Senge, P.M. (2010). The fifth discipline: The art and practice of the learning organization, New York, Crown Publishing Group.

Senge, P.M. (2014). The fifth discipline fieldbook: Strategies and tools for building a learning organization, New York, Crown Business.

Zeeman, A. (2017). Senge's Five Disciplines of Learning Organizations, https://www.toolshero.com/ management/five-disciplines-learning-organizations. 